\title{
Reduced-order thermodynamic models for servo-pneumatic actuator chambers
}

\author{
J Falcão Carneiro ${ }^{1,2 *}$ and F Gomes de Almeida ${ }^{1,2}$ \\ ${ }^{1}$ Departamento de Engenharia Mecânica e Gestão Industrial da Faculdade de Engenharia da Universidade do Port, \\ Porto, Portugal \\ ${ }^{2}$ Instituto de Engenharia Mecânica, IDMEC, Pólo, Portugal
}

The manuscript was received on 14 September 2005 and was accepted after revision for publication on 13 March 2006.

DOI: 10.1243/09596518JSCE203

\begin{abstract}
This paper discusses thermodynamic models of air inside pneumatic actuator chambers. In servo-pneumatics common practice, these models are simplified by neglecting the temperature dynamics. Classical models in the literature assume the temperature inside the pneumatic chamber either to be constant or to follow a polytropic law. Furthermore, the mixing process of air entering the chamber and heat transfer between air and cylinder walls is often neglected or only implicitly taken into account.

This work evaluates the impact of these simplifications and order reductions in the prediction of pressure inside the actuator chamber. Classical models are compared with several others not only taking into account the mixing process but also explicitly including the heat transfer between air and cylinder walls. Simulation studies show that the reduced-order models proposed in this paper can lead to a mean square error in pressure prediction of only 10 per cent of that obtained using classical models.
\end{abstract}

Keywords: servo-pneumatic systems modelling, servo-pneumatic systems simulation

\section{INTRODUCTION}

In order to control a pneumatic actuator accurately, a model of the pneumatic system has to be established. This model includes the pressure and temperature dynamics of the two actuator chambers and the mechanical dynamics of the load. Therefore, even neglecting the servo-valve and friction dynamics, the complete model is a sixth-order model. This is inappropriate for control purposes since it is mathematically difficult to handle and demands a mass or temperature observer as these variables cannot be correctly measured during operation.

Servo-pneumatic systems are used in applications where force or motion control is required. In both situations the pressure inside the chambers is the most relevant thermodynamic state variable since the control goals directly depend on it. Therefore, the most typical solution to reduce the order of the model

* Corresponding author: Faculdade de Engenharia da Universidade do Porto, Rua Dr. Roberto Frias, Porto 4200-465, Portugal.email: jpbrfc@fe.up.pt is to neglect temperature dynamics and to consider a polytropic process with an index ranging from 1 (isothermal process) to 1.4 (adiabatic reversible process). Burrows [1] used a reversible adiabatic approach, Zalmanzon [2], Outbib and Richard [3], and Ning and Bone [4] an isothermal approach, and Andersen [5] and Chitty and Lambert [6] a polytropic approach. Furthermore, examples can be found in the literature [7-10] where, although the pressure dynamic model is deduced assuming that the temperature follows a polytropic law, a further simplification in this model is introduced by neglecting temperature changes with respect to ambient temperature. This approach leads to a situation where the polytropic index of pressure dynamics is tuneable but the temperature is fixed at ambient temperature.

More recently, a new approximate model of a pneumatic cylinder thermodynamic chamber was proposed in reference [11]; based on experimental evidence presented in reference [12], Richer and Hurmuzlu [11] use a polytropic-based model whose singularity resides on the fact that it uses different polytropic indexes. The charging process has an 
adiabatic evolution, the discharging process an isothermal evolution, and the process due to the movement of the piston is assumed to be intermediate between the previous two by accepting a polytropic index equal to 1.2. Again, although the processes are not necessarily isothermal, temperature fluctuations are neglected. The question that naturally arises is whether these approaches, which sometimes do not have physical meaning, provide good thermodynamic models for pressure. Another question is which model to choose among the existing models. Before answering these questions an important issue is to know whether temperature in real servo systems has significant changes over ambient temperature.

As observed in reference [12], when using pneumatic cylinders for on-off movements, both the pressure and the temperature inside the cylinder chamber experience wide variations. In that study, experimentally measured temperatures varied from $263 \mathrm{~K}$ when discharging to $323 \mathrm{~K}$ when charging. When using pneumatic cylinders for servo-control, deviations of temperature from their equilibrium values are less pronounced but are not, as usually considered in the literature, negligible. This fact was experimentally observed in reference [13], where the temperature inside the discharging chamber of a pneumatic cylinder was measured in a meter-out velocity control set-up. In that experiment, temperature changes of approximately $30 \mathrm{~K}$ were measured during a full stroke movement of the piston. Another way of illustrating this fact is to simulate the sixthorder system. For a pneumatic cylinder of $20 \mathrm{~mm}$ diameter and $100 \mathrm{~mm}$ stroke, which is excited by a random white noise reference, a change of approximately $\pm 1.5 \times 10^{5} \mathrm{~Pa}$ around the equilibrium pressure $\left(P_{0}=5.65 \times 10^{5} \mathrm{~Pa}\right)$ leads to temperature changes of approximately 20 and $-30 \mathrm{~K}$ around ambient temperature $(293 \mathrm{~K})$. Full details of this simulation will be given in section 4 for cylinder D, closed-loop simulation.

This paper will focus on the thermodynamic modelling of pneumatic cylinder chambers. As previously explained, different studies use different reduced models but there is not, as far as the present authors know, any work comparing them. This paper intends to shed some light on the subject by comparing different reduced-order models with the full-order model and determining each model performance. Whether using a reduced or a full model, it is important to assess the influence of the heat transfer coefficient between the air inside the cylinder chambers and its walls. The present authors have experimentally determined the heat transfer coefficients for three different industrial pneumatic actuators. Those values were used as guidelines for the simulation studies developed in the present work.

This paper is organized as follows. Section 2 presents the datum model of the servo-pneumatic system used for comparison purposes. Section 3 presents the typical model reductions appearing in the literature and proffers some new approximate reductions. These reduced-order models propose not only different algebraic ways of including temperature but also different ways of taking into account heat transfer through walls. In section 4 the performances of the several models presented in section 3 are compared by means of simulation studies. Finally, the main conclusions are drawn in section 5 .

\section{MODEL OF A SERVO-PNEUMATIC SYSTEM}

\subsection{Servo-valve modelling}

A pneumatic servo-valve model may be partitioned into two parts: a dynamic part for the spool and its actuator motion and a static part for the mass flow stage [9]. The bandwidth of the servo-valve is typically much higher than the bandwidth of the pneumatic actuator. The bandwidth of the system is therefore not limited by the servo-valve and consequently its dynamics are often neglected [9]. This will be the approach followed in this work. Consider a typical four-way servo-valve as schematically presented in Fig. 1.

The air mass flows that cross each restriction 1,2 , 3 , and 4, may be determined using the expression [14]

$$
\begin{aligned}
& \dot{m}\left(x_{\mathrm{v}}, P_{\mathrm{u}}, P_{\mathrm{d}}, T_{\mathrm{u}}\right) \\
& = \begin{cases}A_{\mathrm{t}}\left(x_{\mathrm{v}}\right) P_{\mathrm{u}}\left\{\frac{2 \gamma}{(\gamma-1) R T_{\mathrm{u}}}\left[\left(\frac{P_{\mathrm{d}}}{P_{\mathrm{u}}}\right)^{2 / \gamma}-\left(\frac{P_{\mathrm{d}}}{P_{\mathrm{u}}}\right)^{(\gamma+1) / \gamma}\right]\right\}^{1 / 2} \\
\text { if } \frac{P_{\mathrm{d}}}{P_{\mathrm{u}}}>0.5283 \text { (subsonic) } \\
0.0404 \frac{P_{\mathrm{u}} A_{\mathrm{t}}\left(x_{\mathrm{v}}\right)}{\left(T_{\mathrm{u}}\right)^{1 / 2}} & \text { if } \frac{P_{\mathrm{d}}}{P_{\mathrm{u}}} \leqslant 0.5283 \text { (sonic) }\end{cases}
\end{aligned}
$$

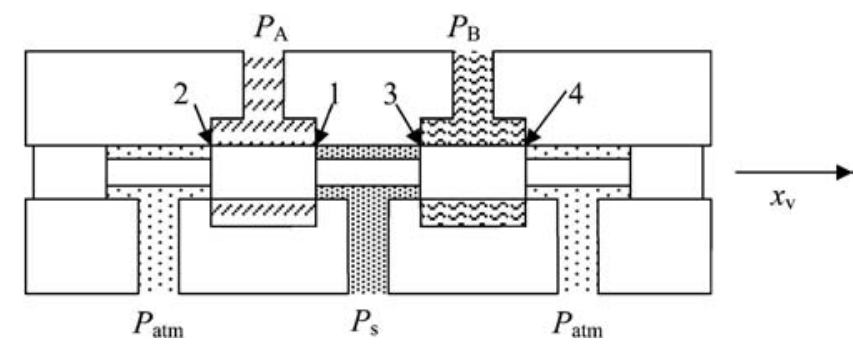

Fig. 1 Servo-valve scheme 
where $x_{\mathrm{v}}$ is the spool displacement and $P_{\mathrm{u}}, T_{\mathrm{u}}, A_{\mathrm{t}}\left(x_{\mathrm{v}}\right)$, and $P_{\mathrm{d}}$ are defined for each restriction in the ideal throat of Fig. 2.

In this work, it is accepted that the areas of the servo-valve restrictions are matched

$$
\left[A_{1}\left(x_{\mathrm{v}}\right)=A_{4}\left(x_{\mathrm{v}}\right) ; A_{2}\left(x_{\mathrm{v}}\right)=A_{3}\left(x_{\mathrm{v}}\right)\right]
$$

and symmetric $\left[A_{1}\left(-x_{\mathrm{v}}\right)=A_{2}\left(x_{\mathrm{v}}\right) ; A_{3}\left(x_{\mathrm{v}}\right)=A_{4}\left(-x_{\mathrm{v}}\right)\right]$. It is also assumed that there is no leakage of air when the spool is at the central position and that $A_{1}\left(x_{\mathrm{v}}\right) \neq 0 \Rightarrow A_{2}\left(x_{\mathrm{v}}\right)=0$ and $A_{3}\left(x_{\mathrm{v}}\right) \neq 0 \Rightarrow A_{4}\left(x_{\mathrm{v}}\right)=0$.

Finally, it is accepted that there are linear relations between the command voltage $u$ and the spool displacement $\left(x_{\mathrm{v}}=k_{\mathrm{u}} u\right)$ and between the spool displacement and the area of each restriction $\left(A_{i}=k_{x} x_{\mathrm{v}}, i=1,2,3,4\right)$.

From these assumptions, the relation between command voltage and each restriction area is given by

$$
u \geqslant 0 \Rightarrow\left\{\begin{array}{l}
A_{1}=k_{\mathrm{u}} k_{x} u, \\
A_{4}=k_{\mathrm{u}} k_{x} u, \\
A_{3}=0, \\
A_{2}=0,
\end{array} \quad u<0 \Rightarrow\left\{\begin{array}{l}
A_{1}=0 \\
A_{4}=0 \\
A_{3}=k_{\mathrm{u}} k_{x} u \\
A_{2}=k_{\mathrm{u}} k_{x} u
\end{array}\right.\right.
$$

Real servo-valves, however, have leakage of air between the spool and sleeve that determines the equilibrium pressure when the spool is at the central position. With the assumptions made above, the equilibrium pressure $P_{0}$ is given by $P_{0}=0.8077 P_{\mathrm{s}}$ (see Appendix 2). In this work the supply pressure is $P_{\mathrm{s}}=7 \times 10^{5} \mathrm{~Pa}$ and therefore $P_{0}=5.65 \times 10^{5} \mathrm{~Pa}$. The equilibrium temperature $T_{0}$ is the ambient temperature assumed to be $T_{\mathrm{amb}}=T_{0}=293 \mathrm{~K}$. It is worth noting that, even with a fairly simple model of the servo-valve, it suits the goals of this work since it is focused on the thermodynamic model of the chambers.

\subsection{Mechanical modelling}

Consider the pneumatic cylinder schematically represented in Fig. 3. Applying Newton's second law results in

$$
M \ddot{x}=P_{\mathrm{A}} A_{\mathrm{A}}-P_{\mathrm{B}} A_{\mathrm{B}}-F_{\mathrm{f}}
$$

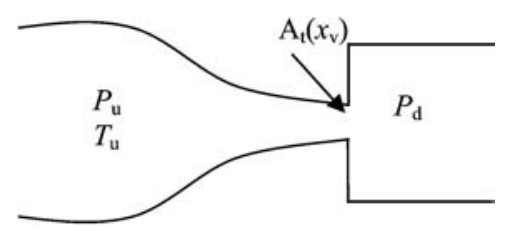

Fig. 2 Ideal throat

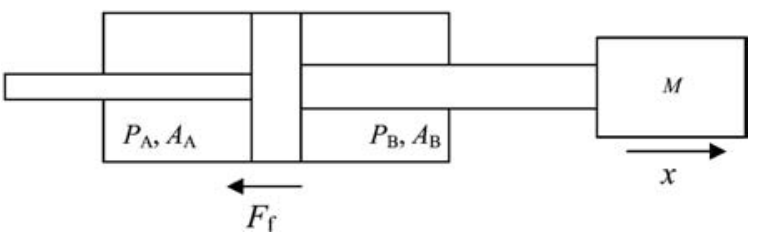

Fig. 3 Scheme of a symmetric cylinder

where $M$ is the external load mass plus the mass of the moving parts of the cylinder. The frictional force $F_{\mathrm{f}}$ is assumed to be entirely viscous $\left(F_{\mathrm{f}}=k_{\mathrm{f}} \dot{x}\right)$. Again, the friction model is quite simple but suitable for the purposes of this work. For more information on friction modelling, see reference $[\mathbf{1 5}]$.

\subsection{Thermodynamic model}

Assuming that air is a perfect gas, that pressures and temperatures are homogeneous inside the chamber, and finally that kinetic and gravitational energies of the fluid, viscous work, and cylinder mass flow leakages are negligible, the Reynolds transport theorem [16] applied to mass and energy in a fixed control volume with one-dimensional inlets and outlets gives

$$
\begin{aligned}
\frac{\mathrm{d} P}{\mathrm{~d} t}= & -\gamma \frac{P}{V} \frac{\mathrm{d} V}{\mathrm{~d} t}+\gamma \frac{R}{V} \dot{m}_{\mathrm{in}} T_{\mathrm{in}}-\gamma \frac{R}{V} \dot{m}_{\text {out }} T-\frac{\gamma-1}{V} \dot{Q} \\
\frac{\mathrm{d} T}{\mathrm{~d} t}= & \frac{T}{V} \frac{\mathrm{d} V}{\mathrm{~d} t}(1-\gamma)-\dot{m}_{\text {out }} \frac{R T^{2}}{V P}(\gamma-1) \\
& +\dot{m}_{\mathrm{in}} \frac{R T}{V P}\left(\gamma T_{\text {in }}-T\right)-\frac{(\gamma-1)}{P V} \dot{Q}
\end{aligned}
$$

In these equations, $\dot{Q}$ is the heat transfer between air inside the cylinder and its walls and $T_{\text {in }}$ is the temperature of air entering the chamber, assumed to be ambient temperature $\left(T_{\mathrm{in}}=T_{\mathrm{amb}}\right)$. This model is widely referenced in the literature as correctly describing temperature and pressure evolution inside a pneumatic chamber $[\mathbf{7}, \mathbf{1 0}, \mathbf{1 7}]$. Therefore, it will be used as the datum model in this work.

\section{MODEL ORDER REDUCTION}

The model given by equations (4) and (5) is not suitable for control purposes for the reasons presented in section 1. In order to simplify this model, the temperature is naturally the state variable to remove since force and motion state directly depend on pressure (see equation (3)). This reduction is usually performed in the literature by considering 
temperature to follow the polytropic law

$$
T=T_{0}\left(\frac{P}{P_{0}}\right)^{(n-1) / n}
$$

Another relevant issue concerns the heat transfer through walls. It is widely accepted (see, for example, references [7], [10], and [17] to [19]) that $\dot{Q}$ can be correctly determined by

$$
\dot{Q}=\lambda(P, T) A_{q}(x)\left(T_{\mathrm{amb}}-T\right)
$$

where

$$
\lambda(P, T)=\lambda_{0}\left(\frac{P T}{P_{0} T_{0}}\right)^{1 / 2}
$$

is the heat transfer coefficient [19]. However, based on the argument that the heat transfer coefficient is difficult to determine, classical works on servopneumatics do not use equation (7). Instead, the perfect gas equation $P V=m R T$ is directly differentiated, giving

$$
\frac{\mathrm{d} P}{\mathrm{~d} t}=-\frac{P}{V} \frac{\mathrm{d} V}{\mathrm{~d} t}+\frac{R}{V} T\left(\dot{m}_{\text {in }}-\dot{m}_{\text {out }}\right)+\frac{P}{T} \frac{\mathrm{d} T}{\mathrm{~d} t}
$$

When using a polytropic model for temperature evolution, equation (9) reduces to

$$
\frac{\mathrm{d} P}{\mathrm{~d} t}=-n \frac{P}{V} \frac{\mathrm{d} V}{\mathrm{~d} t}+n \frac{R}{V} T\left(\dot{m}_{\text {in }}-\dot{m}_{\text {out }}\right)
$$

In the model represented by equation (10), $n$ is the polytropic index that can be adjusted from 1 (isothermal process) to 1.4 (adiabatic process). There are several examples in the literature that use equations (6) and (10) with a further simplification; although to achieve equation (10) a polytropic temperature evolution was assumed, it is common practice to consider that temperature fluctuations over equilibrium temperature are negligible and therefore $T=T_{0}$. For instance, this model was used in reference [3] with $n=1$, in references [7] to [10] with $n$ being experimentally tuned, and in reference [20] with $n=1.4$. In order to compare these different options, models $\mathrm{M}_{1}, \mathrm{M}_{2}$, and $\mathrm{M}_{3}$ are defined as follows.

Model $M_{1}$

$$
\begin{aligned}
& T=T_{0} \\
& \frac{\mathrm{d} P}{\mathrm{~d} t}=-\frac{P}{V} \frac{\mathrm{d} V}{\mathrm{~d} t}+\frac{R}{V} T\left(\dot{m}_{\mathrm{in}}-\dot{m}_{\text {out }}\right)
\end{aligned}
$$

Model $M_{2}$

$$
\begin{aligned}
& T=T_{0} \\
& \frac{\mathrm{d} P}{\mathrm{~d} t}=-n \frac{P}{V} \frac{\mathrm{d} V}{\mathrm{~d} t}+n \frac{R}{V} T\left(\dot{m}_{\text {in }}-\dot{m}_{\text {out }}\right)
\end{aligned}
$$

Model $M_{3}$

$$
\begin{aligned}
& T=T_{0} \\
& \frac{\mathrm{d} P}{\mathrm{~d} t}=-\gamma \frac{P}{V} \frac{\mathrm{d} V}{\mathrm{~d} t}+\gamma \frac{R}{V} T\left(\dot{m}_{\mathrm{in}}-\dot{m}_{\text {out }}\right)
\end{aligned}
$$

Note that, although models $\mathrm{M}_{1}$ and $\mathrm{M}_{3}$ are particular cases of model $\mathrm{M}_{2}$, they will appear individually so that their performance can be directly compared with the other models.

In order to enhance the quality of the previous models, a new model was proposed in reference [11]. Based on experimental evidence presented in reference [12], the model assumes that the incoming flow process is adiabatic, the outgoing flow process is isothermal, and the flow process due to piston movement lies between isothermal and adiabatic processes. This is achieved by considering different polytropic indexes in equation (10): the incoming flow term is affected by $n=1.4$, the outgoing flow by $n=1$, and the piston movement term by $n=1.2$. This model will be called $\mathrm{M}_{4}$ and is defined as follows.

\section{Model $M_{4}$}

$$
\begin{aligned}
& T=T_{0} \\
& \frac{\mathrm{d} P}{\mathrm{~d} t}=-1.2 \frac{P}{V} \frac{\mathrm{d} V}{\mathrm{~d} t}+1.4 \frac{R}{V} T \dot{m}_{\mathrm{in}}-\frac{R}{V} T \dot{m}_{\text {out }}
\end{aligned}
$$

The models presented so far consider that temperature fluctuations over ambient temperature are negligible. In order to study the effects of this assumption, a model similar to $\mathrm{M}_{2}$ but considering temperature changes inside the chamber is considered. It is called $\mathrm{M}_{5}$, was used for simulation purposes in reference [10] with $n=1.2$, and is defined as follows.

Model $M_{5}$

$$
\begin{aligned}
& T=T_{0}\left(\frac{P}{P_{0}}\right)^{(n-1) / n} \\
& \frac{\mathrm{d} P}{\mathrm{~d} t}=-n \frac{P}{V} \frac{\mathrm{d} V}{\mathrm{~d} t}+n \frac{R}{V} T\left(\dot{m}_{\mathrm{in}}-\dot{m}_{\text {out }}\right)
\end{aligned}
$$

Models $\mathrm{M}_{1}$ to $\mathrm{M}_{5}$ are the typical models used in servo-pneumatics literature. All these use a polytropic law for temperature when replacing $\mathrm{d} T / \mathrm{d} t$ in equation (9). As a consequence, these models lose the heat transfer process that occurs by mixing between air entering the chamber and the air inside it. In order to evaluate the impact of this loss, model $\mathrm{M}_{6}$ was defined as being similar to model $\mathrm{M}_{5}$ but with a constant temperature in the incoming flow term. 
Model $M_{6}$

$$
\begin{aligned}
& T=T_{0}\left(\frac{P}{P_{0}}\right)^{(n-1) / n} \\
& \frac{\mathrm{d} P}{\mathrm{~d} t}=-n \frac{P}{V} \frac{\mathrm{d} V}{\mathrm{~d} t}+n \frac{R}{V} \dot{m}_{\mathrm{in}} T_{\mathrm{in}}-n \frac{R}{V} \dot{m}_{\text {out }} T
\end{aligned}
$$

Model $\mathrm{M}_{6}$ ends the set of models where $\dot{Q}$ is calculated in an implicit way. As previously stated, this approach is justified in the classical literature by the difficulty in determining the heat transfer coefficient of equation (8). However, the present authors have developed a simple procedure to estimate it experimentally, based on the thermal time constant method [21], and it is therefore pertinent to evaluate the behaviour of models explicitly accounting for the heat transfer. Furthermore, it would be interesting from a mathematical point of view to simplify the heat transfer model (7). In order to do so, note that a simplified version can be achieved by neglecting temperature and pressure fluctuations with respect to their equilibrium values. The heat transfer coefficient can then be expressed as $\lambda(P, T)=\lambda\left(P_{0}, T_{0}\right)=\lambda_{0}$ and the heat transfer becomes

$$
\dot{Q}=\lambda_{0} A_{q}(x)\left(T_{\mathrm{amb}}-T\right)
$$

Furthermore, considering an average heat transfer area $\bar{A}_{q}$ defined as

$$
\bar{A}_{q}=A_{q}\left(x_{0}\right)=\frac{\pi}{2} \phi^{2}+\left|\pi \phi\left(x_{0}+\frac{l}{2}\right)\right|, \quad x_{0}=0
$$

and a heat conductance $k_{0}$ defined as

$$
k_{0}=\lambda_{0} \bar{A}_{q}
$$

an even more simplified heat transfer model can be obtained by substituting equation (12) into equation (7) to give

$$
\dot{Q}=k_{0}\left(T_{\mathrm{amb}}-T\right)
$$

Using equation (13) as the explicit heat transfer model leads to model $\mathrm{M}_{7}$

Model $M_{7}$

$$
\begin{aligned}
T= & T_{0}\left(\frac{P}{P_{0}}\right)^{(n-1) / n} \\
\frac{\mathrm{d} P}{\mathrm{~d} t}= & -\gamma \frac{P}{V} \frac{\mathrm{d} V}{\mathrm{~d} t}+\gamma \frac{R}{V} T\left(\dot{m}_{\mathrm{in}}-\dot{m}_{\text {out }}\right) \\
& +\frac{\gamma-1}{V} k_{0}\left(T-T_{\mathrm{amb}}\right)
\end{aligned}
$$

Model $\mathrm{M}_{7}$ does not take into account the mixing process, so model $M_{8}$ is defined as similar to model $\mathrm{M}_{7}$ with the mixing process considered.

Model $M_{8}$

$$
\begin{aligned}
T= & T_{0}\left(\frac{P}{P_{0}}\right)^{(n-1) / n} \\
\frac{\mathrm{d} P}{\mathrm{~d} t}= & -\gamma \frac{P}{V} \frac{\mathrm{d} V}{\mathrm{~d} t}+\gamma \frac{R}{V} \dot{m}_{\mathrm{in}} T_{\mathrm{in}}-\gamma \frac{R}{V} \dot{m}_{\mathrm{out}} T \\
& +\frac{\gamma-1}{V} k_{0}\left(T-T_{\mathrm{amb}}\right)
\end{aligned}
$$

Finally, models $M_{9}$ and $M_{10}$ are similar to model $\mathrm{M}_{8}$ but use progressively more complex heat transfer models: model $\mathrm{M}_{9}$ uses equation (11) and model $\mathrm{M}_{10}$ uses equation (7).

Model $M_{9}$

$$
\begin{aligned}
T= & T_{0}\left(\frac{P}{P_{0}}\right)^{(n-1) / n} \\
\frac{\mathrm{d} P}{\mathrm{~d} t}= & -\gamma \frac{P}{V} \frac{\mathrm{d} V}{\mathrm{~d} t}+\gamma \frac{R}{V} \dot{m}_{\mathrm{in}} T_{\mathrm{in}}-\gamma \frac{R}{V} \dot{m}_{\text {out }} T \\
& +\frac{\gamma-1}{V} \lambda_{0} A_{q}(x)\left(T-T_{\mathrm{amb}}\right)
\end{aligned}
$$

Model $M_{10}$

$$
\begin{aligned}
T= & T_{0}\left(\frac{P}{P_{0}}\right)^{(n-1) / n} \\
\frac{\mathrm{d} P}{\mathrm{~d} t}= & -\gamma \frac{P}{V} \frac{\mathrm{d} V}{\mathrm{~d} t}+\gamma \frac{R}{V} \dot{m}_{\mathrm{in}} T_{\mathrm{in}}-\gamma \frac{R}{V} \dot{m}_{\mathrm{out}} T \\
& +\frac{\gamma-1}{V} \lambda_{0} A_{q}(x) \sqrt{\frac{P T}{P_{0} T_{0}}}\left(T-T_{\mathrm{amb}}\right)
\end{aligned}
$$

Note that there are some interesting relations between models implicitly and explicitly accounting for heat transfer through walls; if an adiabatic process is considered in $\mathrm{M}_{7}\left(k_{0}=0 ; n=1.4\right)$, this model is equal to $\mathrm{M}_{5}$ with an adiabatic process $(n=1.4)$. If an adiabatic process is considered in $\mathrm{M}_{8}, \mathrm{M}_{9}$, or $\mathrm{M}_{10}$ $\left(k_{0} ; \lambda_{0}=0 ; n=1.4\right)$, these models are equal to $\mathrm{M}_{6}$ with an adiabatic process $(n=1.4)$. However, if an isothermal model process is considered in $\mathrm{M}_{7}, \mathrm{M}_{8}, \mathrm{M}_{9}$, or $\mathrm{M}_{10}\left(k_{0} ; \lambda_{0}=\infty ; n=1\right)$, these models become equal to $\mathrm{M}_{3}$, which is intended to model adiabatic processes. This inconsistency is justified by the simplification process leading to $\mathrm{M}_{3}$; although the pressure index of $\mathrm{M}_{3}$ is adiabatic, temperature changes are neglected. Table 1 reviews the main features of the reduced models. 
Table 1 Features of the reduced models

\begin{tabular}{lllll}
\hline Model & $\begin{array}{l}\text { Explicit heat transfer } \\
\text { through walls }\end{array}$ & $\begin{array}{l}\text { Heat transfer } \\
\text { by mixing }\end{array}$ & $\begin{array}{l}\text { Temperature } \\
\text { evolution }\end{array}$ & Pressure index \\
\hline$M_{1}$ & $\times$ & $\times$ & Constant & 1 \\
$M_{2}$ & $\times$ & $\times$ & Constant & $n$ \\
$M_{3}$ & $\times$ & $\times$ & Constant & 1.4 \\
$M_{4}$ & $\times$ & $\times$ & Constant & $1,1.2,1.4$ \\
$M_{5}$ & $\times$ & $\times$ & Polytropic & $n$ \\
$M_{6}$ & $\times$ & $\checkmark$ & Polytropic & $n$ \\
$M_{7}$ & $\checkmark$ & $\times$ & Polytropic & $\gamma$ \\
$M_{8}$ & $\sqrt{ }$ & $\checkmark$ & Polytropic & $\gamma$ \\
$M_{9}$ & $\checkmark$ & $\sqrt{ }$ & Polytropic & $\gamma$ \\
$M_{10}$ & $\sqrt{ }$ & $\checkmark$ & Polytropic & $\gamma$ \\
\hline
\end{tabular}

\section{PERFORMANCE COMPARISON}

To compare the performance of the different models when predicting pressure, several simulation studies on two types of symmetrical cylinder were run. The cylinder's features are presented in Table 2. The tool used to perform the simulations was MATLAB/ Simulink with a Dormand-Prince integrator and a fixed integration step of $1 \mathrm{~ms}$.

Each cylinder with the full-order model [equations (4), (5), and (7) for each chamber] was tested in two types of simulation: open-loop (Fig. 4) and closed-loop (proportional) control (Fig. 5). The openloop simulation was excited by a pseudo-random hit sequence (PRBS) signal (implemented with a Gaussian random number generator followed by a sign function) and the closed-loop simulation by a Gaussian random number generator. In order to prevent the piston from reaching the end positions in the open-loop simulation, the sign of the input signal to the valve was forced to change when the

Table 2 Features of the cylinders used to test the performances of the models

\begin{tabular}{lllll}
\hline Actuator & $\begin{array}{l}\phi \\
(\mathrm{mm})\end{array}$ & $\begin{array}{l}l \\
(\mathrm{~mm})\end{array}$ & $V_{\mathrm{d}}\left(\mathrm{m}^{3}\right)$ & $\bar{A}_{q}\left(\mathrm{~m}^{2}\right)$ \\
\hline $\mathrm{D}$ & 20 & 100 & $1.571 \times 10^{-6}$ & $3.77 \times 10^{-3}$ \\
$\mathrm{E}$ & 32 & 275 & $1.106 \mathrm{e} \times 10^{-5}$ & $1.54 \times 10^{-2}$ \\
\hline
\end{tabular}

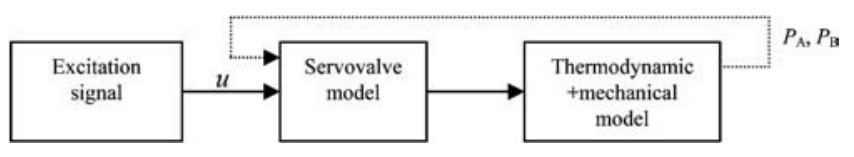

Fig. 4 Open-loop simulation piston reached 96 per cent of half the stroke in each direction. As previously stated in section 2 , the bandwidth of the pneumatic servo-system is limited by the bandwidth of the pneumatic actuator, which typically is lower than $10 \mathrm{~Hz}$. Therefore, the Gaussian and PRBS signals have a bandwidth of approximately $10 \mathrm{~Hz}$ in order to excite the system fully. The most important features of the excitation signals are presented in Table 3.

In terms of servo-valve features, values of $k_{x} k_{\mathrm{u}}=$ $1 \times 10^{-7} \mathrm{~m}^{2} / \mathrm{V}$ for cylinder D and $k_{x} k_{\mathrm{u}}=1 \times 10^{-6} \mathrm{~m}^{2} / \mathrm{V}$ for cylinder $\mathrm{E}$ were assumed. Since the maximum input to the servo-valve was limited to $10 \mathrm{~V}$, these parameters allow a maximum flow (choked flow at supply pressure and ambient temperature) of approximately 100 slpm for cylinder D and 1000 slpm for cylinder E.

The thermal conductance $k_{0}\left[=\lambda_{0} A_{q}\left(x_{0}\right)\right]$ of three industrial actuators was experimentally determined and results ranged from approximately 0.2 to $0.5 \mathrm{~W} / \mathrm{K}$. Therefore, the simulations were made using a central range enclosing these values plus two extreme situations: a very 'adiabatic' $k_{0}=0.02 \mathrm{~W} / \mathrm{K}$ and a very 'isothermal' $k_{0}=2.5 \mathrm{~W} / \mathrm{K}$. The heat transfer coefficients $\lambda_{0}$ for the equilibrium pressure $P_{0}$, temperature $T_{0}$, and $x_{0}=0 \mathrm{~m}$ were determined applying these conductances to the particular cases of cylinders E and D. The results are shown in Table 4.

After running the full-order model simulations, the command signals $u$, position $x$, and velocity $\dot{x}$ were collected to make each of the reduced models run as presented in Fig. 6.

The polytropic index $n$ of the models in section 3 was varied from 1 to 1.4 with a step of 0.5 . Therefore, a total of 912 different simulations (four $k_{0}$

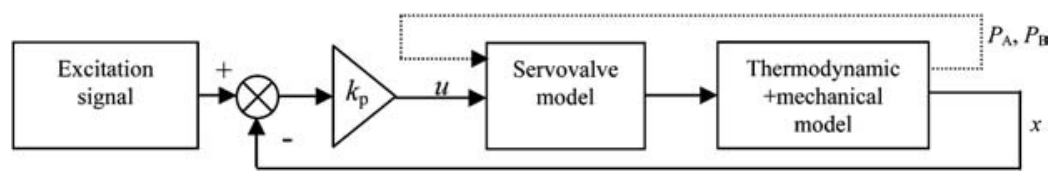

Fig. 5 Closed-loop simulation 
Table 3 Main features of the excitation signals used

\begin{tabular}{|c|c|c|c|c|c|c|}
\hline & & \multicolumn{4}{|c|}{$\begin{array}{l}\text { Generator properties } \\
\text { (random number generator of Simulink) }\end{array}$} & \multirow[b]{2}{*}{$k_{\mathrm{p}}$} \\
\hline & & Mean & Variance & Initial seed & Sample time (s) & \\
\hline \multirow[t]{2}{*}{ Open loop } & Cylinder D & $0(\mathrm{~V})$ & $0.0003\left(\mathrm{~V}^{2}\right)$ & 666 & 0.05 & - \\
\hline & Cylinder E & $0(\mathrm{~V})$ & $0.3\left(\mathrm{~V}^{2}\right)$ & 777 & 0.05 & - \\
\hline \multirow[t]{2}{*}{ Closed loop } & Cylinder D & $0(\mathrm{~m})$ & $0.0003\left(\mathrm{~m}^{2}\right)$ & 666 & 0.05 & 1000 \\
\hline & Cylinder E & $0(\mathrm{~m})$ & $0.0021\left(\mathrm{~m}^{2}\right)$ & 777 & 0.05 & 70 \\
\hline
\end{tabular}

Table 4 Heat transfer coefficients used in the simulation study

\begin{tabular}{lllll}
\hline & \multicolumn{4}{c}{$\lambda_{0}\left(\mathrm{~W} / \mathrm{K} \mathrm{m}^{2}\right)$} \\
\cline { 2 - 5 } & $k_{0}=0.02 \mathrm{~W} / \mathrm{K}$ & $k_{0}=0.1 \mathrm{~W} / \mathrm{K}$ & $k_{0}=0.5 \mathrm{~W} / \mathrm{K}$ & $k_{0}=2.5 \mathrm{~W} / \mathrm{K}$ \\
\hline Cylinder D & 5.3 & 26.5 & 132.6 & 663.1 \\
Cylinder E & 1.29 & 6.48 & 32.4 & 162.0 \\
\hline
\end{tabular}

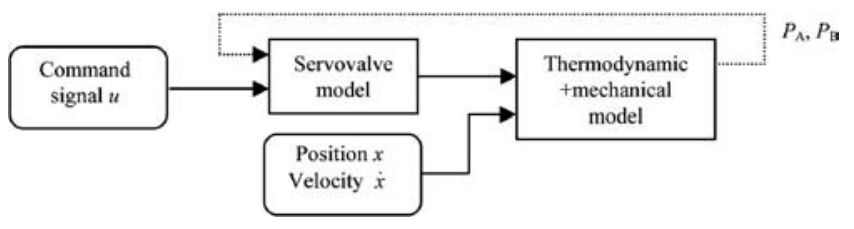

Fig. 6 Simulation of reduced models

values; two cylinders; two types of simulation; six models with nine $n$ values and three models with constant $n$ values) were needed. Each combination $k_{0}$-cylinder-type will be called an experiment $\mathrm{E}_{j}$ $(j=1,2, \ldots, 16)$, according to the coding used in Table 5.

An important question is how to determine the simulation time in order to guarantee an informative experiment. For linear systems, this problem can be solved by determining the settling time of the system's free response. However, for non-linear systems, this is still an open problem and, in order to circumvent it, the settling time $t_{\mathrm{s}}$ of the non-linear equations describing the cylinder behaviour was (over)estimated. This was done in simulation by providing a constant zero excitation signal to the system, applying an external force to move the piston and then releasing the force, which caused the cylinder to move to an equilibrium position. Note that in the open-loop simulation the cylinder's inlets and outlets are permanently closed during the experiment since the servo-valve is assumed to have no leakage. These simulations were run for all the heat transfer coefficients considered in this work, for cylinders D and $\mathrm{E}$ and for the open- and closed-loop simulations. In each of these, the settling time of pressure and temperature were determined using a 1 per cent criterion. As an example, Fig. 7 presents the results obtained with this simulation for cylinder D, closed- loop simulation, and $k_{0}=2.5 \mathrm{~W} / \mathrm{K}$. The initial pressure and temperature of chambers $\mathrm{A}$ and $\mathrm{B}$ are $P_{0}$ and $T_{0}$ and the piston's initial position is $x=0$. A force of $300 \mathrm{~N}$ (Fig. 7(a)) is applied at time 0, causing the piston to move against an end stop positioned at $x=-0.015 \mathrm{~m}$ (Fig. $7(\mathrm{~b})$ ). The force is maintained until stationary conditions are reached. This happens at time $1.267 \mathrm{~s}$; so at this instant the force is released. The evolution behaviours of pressure and temperature in chamber $A$ and of pressure and temperature in chamber B are presented in Figs 7(c), (d), (e), and (f) respectively. The settling times were calculated using a 1 per cent criterion applied to the $\Delta P$ and $\Delta T$ values defined in these figures. The final pressure and temperature of chamber $\mathrm{A}$ and the final pressure and temperature of chamber $\mathrm{B}$ in this example are $P_{\mathrm{A}}=5.276 \times 10^{5} \mathrm{~Pa}, T_{\mathrm{A}}=292.93 \mathrm{~K}$, $P_{\mathrm{B}}=5.294 \times 10^{5} \mathrm{~Pa}$, and $T_{\mathrm{B}}=293.12 \mathrm{~K}$ respectively. Table 5 presents the settling times obtained for all the experiments.

The values underlined in Table 5 are the highest settling times for each cylinder and experiment. The simulation times used for performance comparison (Table 6) were chosen to be at least ten times higher than these values. The performance criterion was the error between the pressure given by the complete model (equations (4), (5), and (7)) and the pressure given by each of the models presented in section 3 . In order to take into account pressure in both chambers, the error vector analysed was the concatenation of the error in chamber A with the error in chamber B.

Considering the results obtained by each model with $n$ leading to the lowest mean square error (MSE) (Fig. 8), it is seen that model $\mathrm{M}_{4}$ has clearly worse results than all the others, and will be therefore 


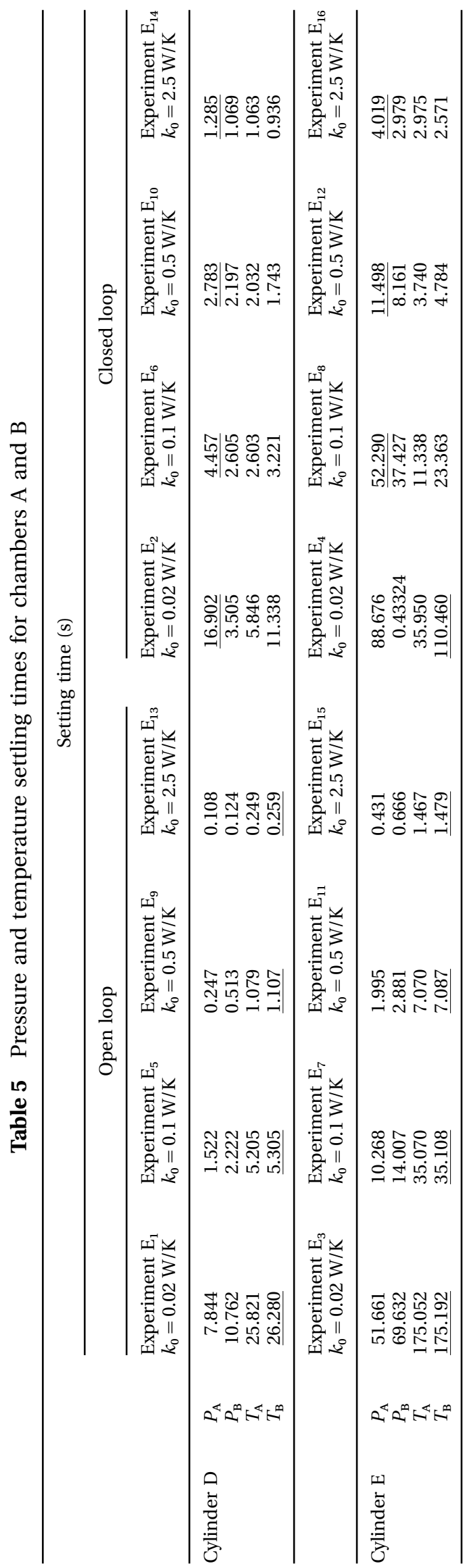

excluded from most of further comparisons. On the other hand, there is no unique best model for all experiments; so the selected performance criterion was the average mean square error ( $\overline{\mathrm{MSE}}$ ) defined as

$$
\overline{\operatorname{MSE}}_{\mathrm{M}_{i}}=\frac{1}{N_{\mathrm{E}}} \sum_{j}^{N_{\mathrm{E}}} \mathrm{MSE}_{\mathrm{M}_{i} \mathrm{E}_{j}}
$$

In equation (14), $\mathrm{M}_{i}$ stands for the model $i$, $i=1,2, \ldots, 10$ and $N_{\mathrm{E}}$ is the total number of experiences $\left(N_{\mathrm{E}}=16\right)$. Figure 9 presents the average MSE, the 10 per cent and 90 per cent percentiles of the MSE for each model on a logarithmic scale. Three levels of error appear: the 'high' level consisting of models $M_{1}, M_{2}$, and $M_{3}$, the 'central' level consisting of models $\mathrm{M}_{5}$ and $\mathrm{M}_{6}$, and the 'low' level consisting of models $M_{7}, M_{8}, M_{9}$, and $M_{10}$.

Analysing the six best models (Fig. 10), the best performance are achieved by models $\mathrm{M}_{7}, \mathrm{M}_{8}, \mathrm{M}_{9}$, and $\mathrm{M}_{10}$, which are essentially indistinguishable. These results suggest that the best reduced models are $M_{7}, M_{8}, M_{9}$, or $M_{10}$. Naturally, among these models, $M_{7}$ would be the natural choice since it is the simplest.

In terms of the expected error and dispersion of the models, and to cope with the different experiments, the expected value $\mu$ and standard deviation $\sigma$ of the error were determined as [22]

$$
\begin{aligned}
\mu_{\mathrm{M}_{i}} & =\frac{1}{N_{\mathrm{E}}} \sum_{\mathrm{E}_{j}} \mu_{\mathrm{M}_{i}, \mathrm{E}_{j}} \\
\sigma_{\mathrm{M}_{i}} & =\left[\frac{1}{N_{\mathrm{E}}} \sum_{\mathrm{E}_{j}} \sigma_{\mathrm{M}_{i}, \mathrm{E}_{j}}^{2}+\sigma^{2}\left(\mu_{\mathrm{M}_{i}, \mathrm{E}_{j}}\right)\right]^{1 / 2}
\end{aligned}
$$

Table 7 presents the overall performance results for all reduced-order models.

These results reveal the following.

1. Model $\mathrm{M}_{4}$, although intended to be a compromise between the inlet and outlet processes, gives the worst results in this comparison.

2. Taking into account temperature changes inside the pneumatic chamber can significantly reduce the pressure prediction error: model $\mathrm{M}_{5}$ has at most 40 per cent of the average MSE of models with fixed temperature (Models $M_{1}, M_{2}$, and $M_{3}$ ).

3. Although modelling the mixing process can slightly reduce the pressure prediction error (model $\mathrm{M}_{6}$ has an average MSE of about 85 per cent of model $\mathrm{M}_{5}$ ), a more significant error drop is obtained when taking into account heat transfer through walls; models $\mathrm{M}_{7}, \mathrm{M}_{8}, \mathrm{M}_{9}$, and $\mathrm{M}_{10}$ have at most 63 per cent of the average MSE of the best model not including it (model $\mathrm{M}_{6}$ ). 

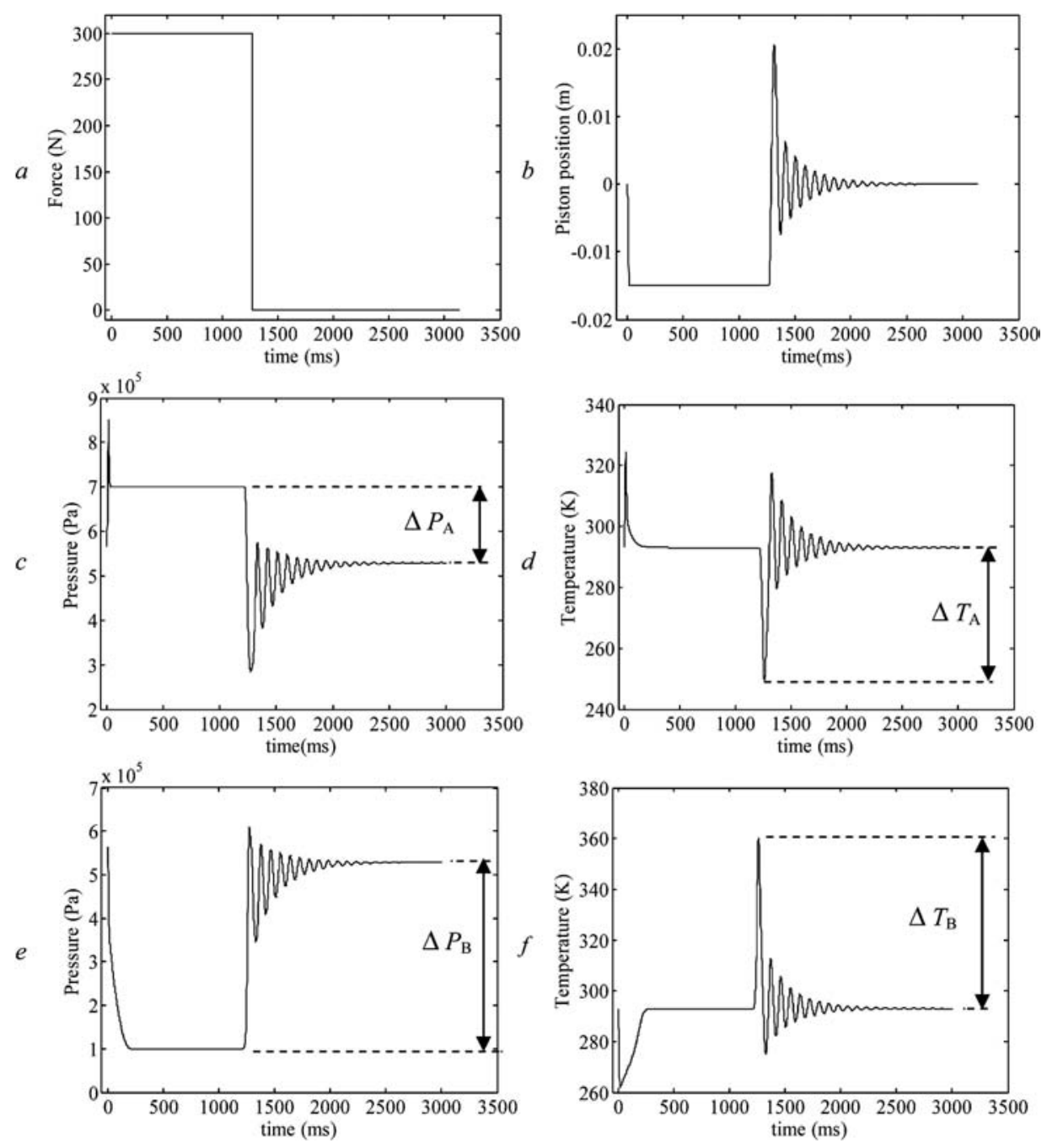

Fig. 7 Determining the minimum simulation time required to perform an informative experiment

Table 6 Simulation times

\begin{tabular}{|c|c|c|c|c|c|c|c|c|}
\hline & \multicolumn{8}{|c|}{ Simulation time (s) } \\
\hline & \multicolumn{4}{|c|}{ Open loop } & \multicolumn{4}{|c|}{ Closed loop } \\
\hline & $k_{0}=0.02 \mathrm{~W} / \mathrm{K}$ & $k_{0}=0.1 \mathrm{~W} / \mathrm{K}$ & $k_{0}=0.5 \mathrm{~W} / \mathrm{K}$ & $k_{0}=2.5 \mathrm{~W} / \mathrm{K}$ & $k_{0}=0.02 \mathrm{~W} / \mathrm{K}$ & $k_{0}=0.1 \mathrm{~W} / \mathrm{K}$ & $k_{0}=0.5 \mathrm{~W} / \mathrm{K}$ & $k_{0}=2.5 \mathrm{~W} / \mathrm{K}$ \\
\hline Cylinder D & 300 & 60 & 60 & 60 & 300 & 60 & 60 & 60 \\
\hline Cylinder E & 1800 & 360 & 120 & 60 & 1200 & 600 & 120 & 60 \\
\hline
\end{tabular}

4. There is not sufficient evidence of performance gain by considering heat transfer dependences on area, pressure, and temperature.

However, there is a practical shortcoming in these results; they were derived using the best $n$ parameter for each model and experiment which is not, for the six best models, constant (Table 8).

From a practical standpoint, it would be useful that, given an experimental $k_{0}$ measure of a pneumatic cylinder, the best model and the (constant) $n$ parameter to use could be determined. This should be done for different 'levels' of heat transfer: an 'adiabatic' level corresponding to $k_{0}=0.02$ and $k_{0}=0.1 \mathrm{~W} / \mathrm{K}$, a 'typical' level corresponding to $k_{0}=0.1$ and $k_{0}=0.5 \mathrm{~W} / \mathrm{K}$ and an 'isothermal' level corresponding to $k_{0}=0.5$ and $k_{0}=2.5 \mathrm{~W} / \mathrm{K}$. Results from this exercise are presented in Table 9.

Figure 11 presents the average MSE and the 90 per cent and the 10 per cent percentiles of the MSE on 


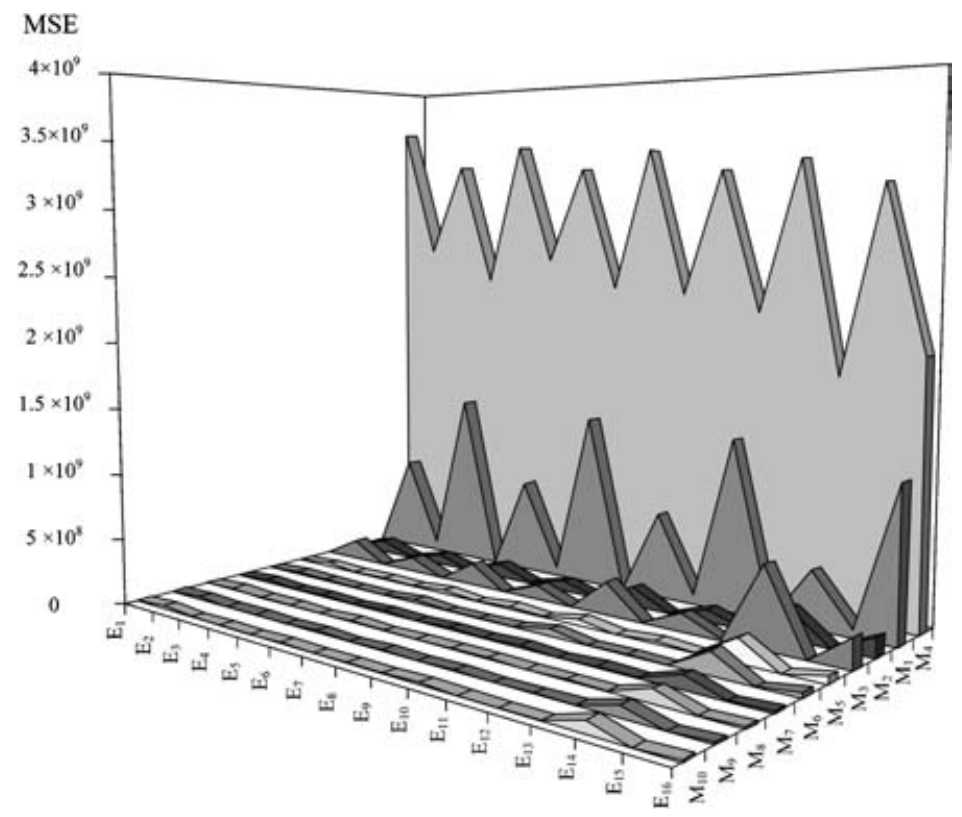

Fig. 8 Average mean square error for all models

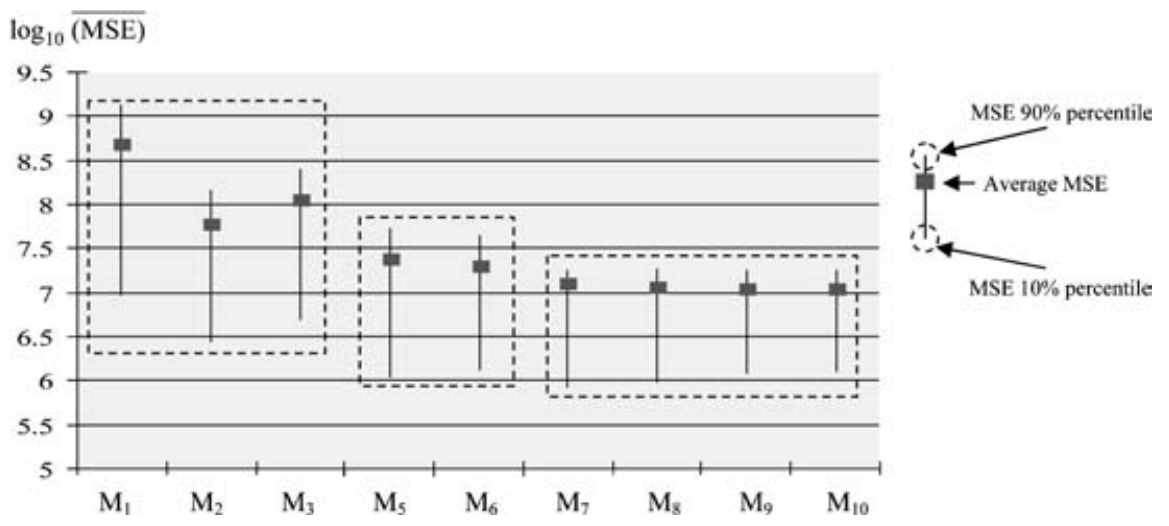

Fig. 9 Performance comparison: $\log _{10}$ (MSE) for the nine best models

Table 7 Expected values, standard deviation and average MSE for all models

\begin{tabular}{lrll}
\hline & & & \\
Model & $\mu_{\mathrm{M}_{i}}(\mathrm{~Pa})$ & $\sigma_{\mathrm{M}_{i}}(\mathrm{~Pa})$ & $\overline{\mathrm{MSE}}_{\mathrm{M}_{i}}\left(\mathrm{~Pa}^{2}\right)$ \\
\hline $\mathrm{M}_{1}$ & $-1.02 \times 10^{4}$ & $1.99 \times 10^{4}$ & $4.96 \times 10^{8}$ \\
$\mathrm{M}_{2}$ & $1.76 \times 10^{3}$ & $7.62 \times 10^{3}$ & $6.11 \times 10^{7}$ \\
$\mathrm{M}_{3}$ & $5.63 \times 10^{3}$ & $9.19 \times 10^{3}$ & $1.15 \times 10^{8}$ \\
$\mathrm{M}_{4}$ & $-4.99 \times 10^{4}$ & $1.87 \times 10^{4}$ & $2.84 \times 10^{9}$ \\
$\mathrm{M}_{5}$ & $6.74 \times 10^{2}$ & $4.89 \times 10^{3}$ & $2.43 \times 10^{7}$ \\
$\mathrm{M}_{6}$ & $5.45 \times 10^{2}$ & $4.53 \times 10^{3}$ & $2.08 \times 10^{7}$ \\
$\mathrm{M}_{7}$ & $-6.14 \times 10^{1}$ & $3.61 \times 10^{3}$ & $1.30 \times 10^{7}$ \\
$\mathrm{M}_{8}$ & $1.07 \times 10^{2}$ & $3.41 \times 10^{3}$ & $1.16 \times 10^{7}$ \\
$\mathrm{M}_{9}$ & $1.21 \times 10^{2}$ & $3.35 \times 10^{3}$ & $1.12 \times 10^{7}$ \\
$\mathrm{M}_{10}$ & $8.04 \times 10^{1}$ & $3.37 \times 10^{3}$ & $1.13 \times 10^{7}$ \\
\hline
\end{tabular}

a logarithmic scale. It is interesting to note that the three performance levels highlighted in Fig. 9 also appear for constant $n$ values and furthermore their relative performances are the same. The importance of modelling temperature changes inside the cylinder chamber is once again revealed since model $\mathrm{M}_{5}$ gives at most about 50 per cent of the average MSE of models with fixed temperature (models $\mathrm{M}_{1}, \mathrm{M}_{2}$, and $\mathrm{M}_{3}$ ). Furthermore, this value is reduced to 30 per cent for typical $k_{0}$ values. Modelling the mixing process slightly enhances the results since model $M_{6}$ has at most 96 per cent of the error of models not considering it (model $\mathrm{M}_{5}$ ) and this value is reduced to about 88 per cent for typical $k_{0}$ values. The average MSE of models including direct heat transfer through walls $\left(\mathrm{M}_{7}, \mathrm{M}_{8}, \mathrm{M}_{9}\right.$, and $\left.\mathrm{M}_{10}\right)$ are at most approximately 72 per cent of the models not considering it (model $\mathrm{M}_{6}$ ). Once again, there is not a significant difference between models $M_{7}, M_{8}, M_{9}$, and $M_{10}$.

Finally, for $k_{0}$ values belonging to the range of typical industrial actuators, the model with best results when balancing performance and complexity 


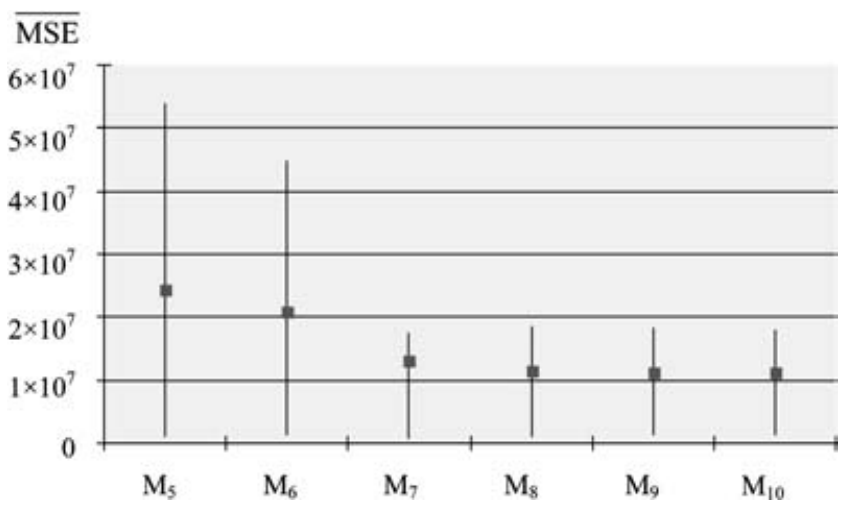

Fig. 10 Performance comparison: mean MSE for the six best models

Table 8 Best $n$ for the six best models

\begin{tabular}{lllllll}
\hline & \multicolumn{6}{c}{ Best $n$} \\
\cline { 2 - 7 } Experiment & $\mathrm{M}_{5}$ & $\mathrm{M}_{6}$ & $\mathrm{M}_{7}$ & $\mathrm{M}_{8}$ & $\mathrm{M}_{9}$ & $\mathrm{M}_{10}$ \\
\hline $\mathrm{E}_{1}$ & 1.35 & 1.30 & 1.35 & 1.40 & 1.40 & 1.40 \\
$\mathrm{E}_{2}$ & 1.40 & 1.35 & 1.40 & 1.40 & 1.40 & 1.40 \\
$\mathrm{E}_{3}$ & 1.40 & 1.40 & 1.35 & 1.40 & 1.40 & 1.40 \\
$\mathrm{E}_{4}$ & 1.40 & 1.40 & 1.40 & 1.40 & 1.40 & 1.40 \\
$\mathrm{E}_{5}$ & 1.35 & 1.30 & 1.25 & 1.40 & 1.40 & 1.40 \\
$\mathrm{E}_{6}$ & 1.40 & 1.35 & 1.40 & 1.40 & 1.40 & 1.40 \\
$\mathrm{E}_{7}$ & 1.40 & 1.35 & 1.35 & 1.40 & 1.40 & 1.40 \\
$\mathrm{E}_{8}$ & 1.40 & 1.40 & 1.40 & 1.40 & 1.40 & 1.40 \\
$\mathrm{E}_{9}$ & 1.30 & 1.25 & 1.15 & 1.15 & 1.15 & 1.15 \\
$\mathrm{E}_{10}$ & 1.35 & 1.35 & 1.35 & 1.30 & 1.35 & 1.35 \\
$\mathrm{E}_{11}$ & 1.40 & 1.35 & 1.25 & 1.35 & 1.35 & 1.35 \\
$\mathrm{E}_{12}$ & 1.40 & 1.40 & 1.35 & 1.30 & 1.35 & 1.35 \\
$\mathrm{E}_{13}$ & 1.15 & 1.15 & 1.05 & 1.05 & 1.05 & 1.05 \\
$\mathrm{E}_{14}$ & 1.25 & 1.20 & 1.15 & 1.15 & 1.15 & 1.15 \\
$\mathrm{E}_{15}$ & 1.35 & 1.35 & 1.10 & 1.15 & 1.15 & 1.15 \\
$\mathrm{E}_{16}$ & 1.35 & 1.35 & 1.20 & 1.15 & 1.20 & 1.20 \\
\hline
\end{tabular}

is model $\mathrm{M}_{7}$ with $n=1.35$. It is essentially undistinguishable from models $\mathrm{M}_{8}, \mathrm{M}_{9}$, and $\mathrm{M}_{10}$ and has an average MSE of about 40 per cent of model $M_{6}$, the next model in terms of performance. Further- more, it has only about 10 per cent of the error of classical isothermal, polytropic, and adiabatic models. The expected value of pressure prediction error with $\mathrm{M}_{7}$ is $140 \mathrm{~Pa}$ with a standard deviation of $2400 \mathrm{~Pa}$.

\section{CONCLUSIONS}

This work has focused on the thermodynamic model of air inside a pneumatic cylinder chamber. Although the use of reduced-order models to describe the pressure evolution is widespread, the choice of which model to select is typically made in an ad hoc way.

In order to guide this choice, a comparison between classical reduced-order models and some new models based on the heat transfer coefficient and thermal conductance of the cylinder was performed. It was shown that the pressure prediction of reduced-order models can be enhanced by considering, first, the explicit heat transfer between cylinder walls and air inside its chambers and second, temperature changes of air inside the cylinder.

For typical heat transfer coefficients of industrial pneumatic actuators, considering these factors may lead to an average MSE in pressure prediction of only 10 per cent of the MSE obtained when using classical isothermal, adiabatic, or polytropic models.

\section{ACKNOWLEDGEMENTS}

The authors would like to acknowledge Professor Sarsfield Cabral for his help on statistical topics. This work has been partially funded by Fundação para a Ciência e Tecnologia under the programme POCTI.

Table 9 Expected value, standard deviation and average MSE for all models with the best constant $n$

\begin{tabular}{|c|c|c|c|c|c|c|c|c|c|}
\hline \multirow[b]{2}{*}{ Model } & \multicolumn{3}{|c|}{$k_{0}=0.02, k_{0}=0.1 \mathrm{~W} / \mathrm{K}$} & \multicolumn{3}{|c|}{$k_{0}=0.1, k_{0}=0.5 \mathrm{~W} / \mathrm{K}$} & \multicolumn{3}{|c|}{$k_{0}=0.5, k_{0}=2.5 \mathrm{~W} / \mathrm{K}$} \\
\hline & $\begin{array}{l}\mu_{\mathrm{M}_{i}} \\
\left(\times 10^{2} \mathrm{~Pa}\right)\end{array}$ & $\begin{array}{l}\sigma_{\mathrm{M}_{i}} \\
\left(\times 10^{3} \mathrm{~Pa}\right)\end{array}$ & $\begin{array}{l}\overline{\mathrm{MSE}} \\
\left(\times 10^{6} \mathrm{~Pa}^{2}\right)\end{array}$ & $\begin{array}{l}\mu_{\mathrm{M}_{i}} \\
\left(\times 10^{2} \mathrm{~Pa}\right)\end{array}$ & $\begin{array}{l}\sigma_{\mathrm{M}_{i}} \\
\left(\times 10^{3} \mathrm{~Pa}\right)\end{array}$ & $\begin{array}{l}\overline{\mathrm{MSE}} \\
\left(\times 10^{6} \mathrm{~Pa}^{2}\right)\end{array}$ & $\begin{array}{l}\mu_{\mathrm{M}_{i}} \\
\left(\times 10^{2} \mathrm{~Pa}\right)\end{array}$ & $\begin{array}{l}\sigma_{\mathrm{M}_{i}} \\
\left(\times 10^{3} \mathrm{~Pa}\right)\end{array}$ & $\begin{array}{l}\overline{\mathrm{MSE}} \\
\left(\times 10^{6} \mathrm{~Pa}^{2}\right)\end{array}$ \\
\hline $\mathrm{M}_{1}$ & -110 & 21.0 & 530 & -110 & 20.0 & 520 & -93.0 & 20.0 & 460 \\
\hline $\mathrm{M}_{2}$ & 8.80 & 6.7 & 46.0 & 14.0 & 7.30 & 55.0 & 9.30 & 9.90 & 97.0 \\
\hline $\mathrm{M}_{3}$ & 46.0 & 7.10 & 70.0 & 52.0 & 7.90 & 87.0 & 66.0 & 11.0 & 160 \\
\hline $\mathrm{M}_{4}$ & -510 & 19.0 & 3000 & -500 & 19.0 & 2900 & -490 & 18 & 2700 \\
\hline $\mathrm{M}_{6}$ & 9.60 & 2.60 & 7.80 & 9.60 & 3.60 & 14.0 & 15.0 & 6.60 & 45.0 \\
\hline $\mathrm{M}_{7}$ & 1.47 & 2.78 & 7.72 & -2.37 & 2.77 & 7.58 & -4.72 & 5.29 & 27.5 \\
\hline $\mathrm{M}_{8}$ & 5.50 & 2.30 & 5.50 & 1.40 & 2.40 & 5.60 & -2.40 & 5.20 & 26.0 \\
\hline $\mathrm{M}_{9}$ & 5.20 & 2.30 & 5.50 & -0.047 & 2.40 & 5.60 & -6.30 & 5.10 & 26.0 \\
\hline $\mathrm{M}_{10}$ & 5.50 & 2.30 & 5.60 & -0.860 & 2.37 & 5.50 & -2.40 & 5.10 & 26.0 \\
\hline
\end{tabular}




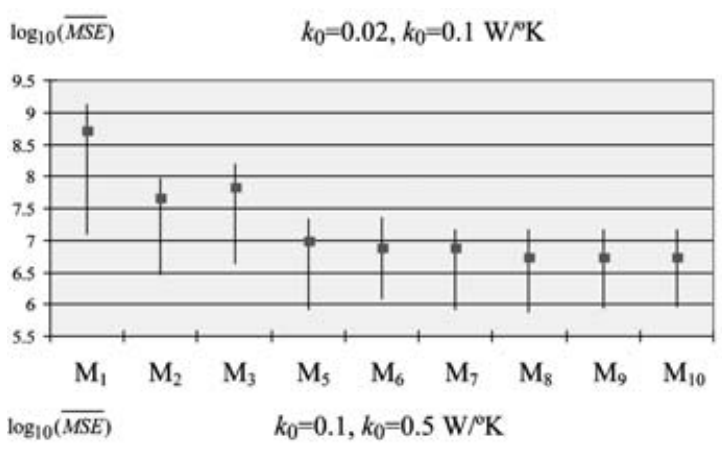

\begin{tabular}{|c|c|}
\hline Model & $\begin{array}{c}\text { Best } \\
\text { constant } \mathrm{n}\end{array}$ \\
\hline $\mathrm{M}_{1}$ & 1 \\
$\mathrm{M}_{2}$ & 1.3 \\
$\mathrm{M}_{3}$ & 1.4 \\
$\mathrm{M}_{5}$ & 1.4 \\
$\mathrm{M}_{6}$ & 1.4 \\
$\mathrm{M}_{7}$ & 1.4 \\
$\mathrm{M}_{8}$ & 1.4 \\
$\mathrm{M}_{9}$ & 1.4 \\
$\mathrm{M}_{10}$ & 1.4 \\
\hline
\end{tabular}

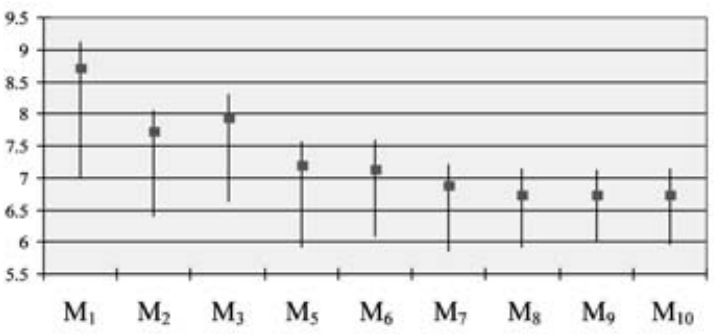

\begin{tabular}{|c|c|}
\hline Model & $\begin{array}{c}\text { Best } \\
\text { constant } n\end{array}$ \\
\hline $\mathrm{M}_{1}$ & 1 \\
$\mathrm{M}_{2}$ & 1.3 \\
$\mathrm{M}_{3}$ & 1.4 \\
$\mathrm{M}_{5}$ & 1.4 \\
$\mathrm{M}_{6}$ & 1.4 \\
$\mathrm{M}_{7}$ & 1.35 \\
$\mathrm{M}_{8}$ & 1.35 \\
$\mathrm{M}_{9}$ & 1.35 \\
$\mathrm{M}_{10}$ & 1.4 \\
\hline
\end{tabular}

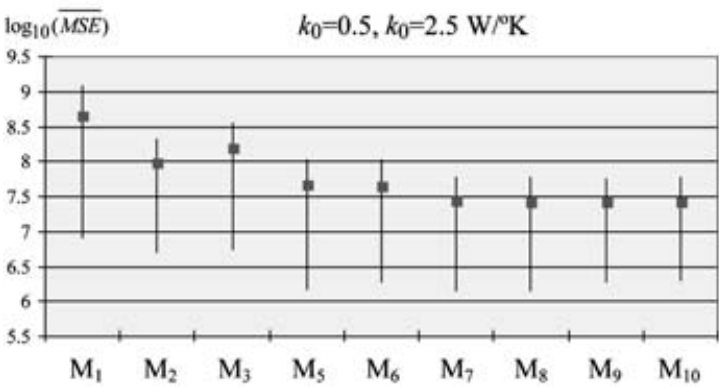

\begin{tabular}{|c|c|}
\hline Model & $\begin{array}{c}\text { Best } \\
\text { constant } \mathrm{n}\end{array}$ \\
\hline $\mathrm{M}_{1}$ & 1 \\
$\mathrm{M}_{2}$ & 1.25 \\
$\mathrm{M}_{3}$ & 1.4 \\
$\mathrm{M}_{5}$ & 1.35 \\
$\mathrm{M}_{6}$ & 1.35 \\
$\mathrm{M}_{7}$ & 1.2 \\
$\mathrm{M}_{8}$ & 1.2 \\
$\mathrm{M}_{9}$ & 1.2 \\
$\mathrm{M}_{10}$ & 1.2 \\
\hline
\end{tabular}

Fig. 11 Performance of all the models except $\mathrm{M}_{4}$ for three levels of heat transfer with the best constant $n$

\section{REFERENCES}

1 Burrows, C. R. Effect of position on the stability of pneumatic servosystems. Proc. Instn Mech. Engrs, Part C: J. Mechanical Engineering Science, 1969, $11(6)$.

2 Zalmazon, L. A. Components for pneumatic control instruments, 1965 (Pergamon, Oxford).

3 Outbib, R. and Richard, E. State feedback stabilization of an electropneumatic system. Trans. ASME, J. Dynamic Systems, Measmt, Control, 2000, 122(3), 410-415.

4 Ning, S. and Bone, G. M. High steady-state accuracy pneumatic servo positioning system with PVA/PV control and friction compensation. In Proceedings of the IEEE International Conference on Robotics and automation, Washington, DC, 2002, pp. 2824-2829 (IEEE, New York).

5 Andersen, B. W. The analysis and design of pneumatic systems, 1976 (John Wiley, New York).

6 Chitty, A. and Lambert, T. H. Modelling a loaded two way pneumatic actuator. J. Measmt Control, 1976, 9(1), 19-25.

7 Richard, E. De la commande lineaire et non lineaire en position des systems electropneumatiques. $\mathrm{PhD}$
Thesis, Institut National des Sciences Amphquées, Lyon, 1990.

8 Richard, E. and Scavarda, S. Comparison between linear and nonlinear control of an electropneumatic servodrive. Trans. ASME, J. Dynamic Systems, Measmt, Control, 1996, 118, 245-252.

9 Brun, X., Belgharbi, M., Sesmat, S., Thomasset, D., and Scavarda, S. Control of an electropneumatic actuator: comparison between some linear and non-linear laws. Proc. Instn Mech. Engrs, Part I: J. Systems and Control Engineering, 1999, 213(5), 387-406.

10 Brun, X. Commandes linéaires et non linéaires en électropneumatique. Methodologies et applications. $\mathrm{PhD}$ Thesis, Institut National des Sciences Amphquées, Lyon, 1999.

11 Richer, E. and Hurmuzlu, Y. A high performance pneumatic force actuator system: part I - nonlinear mathematical model. Trans. ASME, J. Dynamic Systems, Measmt, Control, 2000, 122, 416-425.

12 Al-Ibrahim, A. M. and Otis, P. D. R. Transient air temperature and pressure measurements during charging and discharging processes of an actuating pneumatic cylinder. In International Fluid Power Exposition and Technical Conference, 1992. 
13 Toshiharu, K., Tokashiki, L., and Fujita, T. Influence of air temperature change on equilibrium velocity of pneumatic cylinders. Trans. ASME, J. Dynamic Systems, Measmt, Control, 2002, 124(2), 336-341.

14 McCloy, D. and Martin, H. R. Control of fluid power: analysis and design. Engineering science, 1980 (Ellis Horwood, Chichester, West Sussex).

15 Armstrong-Hélouvry, B., Dupont, P., and Canudas de Wit, C. A survey of models, analysis tools and compensation methods for the control of machines with friction. Automatica, 1994, 30, 1083-1138.

16 White, F. Fluid mechanics, 1994 (McGraw-Hill, New York).

17 French, I. G. and Cox, C. S. Modelling, design and control of a modern electropneumatic actuator. IEE Proc., 1990, 137(3), 145-155.

18 Kagawa, T., Tokashiki, L., and Fujita, T. Influence of air temperature change on equilibrium velocity of pneumatic cylinders. Trans. ASME, J. Dynamic Systems, Measmt, Control, 2002, 124, 336-341.

19 Det, F., Scavarda, S., and Richard, E. Simulated and experimental study of charging and discharging of a cylinder by using an electro-pneumatic servovalve. In JHPS International Symposium on Fluid power, 1989, pp. 199-206.

20 Pandian, S., Hayakawa, Y., Kanazawa, Y., Kamoyama, Y., and Kawamura, S. Practical design of a sliding mode controller for pneumatic actuators. Trans. ASME, J. Dynamic Systems, Measmt, Control, 1997, 119, 666-674.

21 Otis, D. R. and Pourmovahead, A. An experimental thermal time constant correlation for hydraulic accumulators. Trans. ASME, J. Dynamic Systems, Measmt, Control, 1990, 112, 116-121.

22 Guimarães, R. and Cabral, J. Estatística, 1999 (McGraw-Hill, Lisboa).

\section{APPENDIX 1}

\section{Notation}

$A_{\mathrm{A}}, A_{\mathrm{B}}$
$A_{q}$
$\bar{A}_{q}$
$A_{\mathrm{t}}$
$A_{1}, A_{2}, A_{3}, A_{4}$
$\mathrm{E}_{j}$
$F_{\mathrm{f}}$
$k_{\mathrm{f}}$
$k_{x}, k_{\mathrm{u}}$
$k_{0}$
$l$
$\dot{m}$

areas of chambers A and B

respectively $\left(\mathrm{m}^{2}\right)$

heat transfer area $\left(\mathrm{m}^{2}\right)$

average heat transfer area $\left(\mathrm{m}^{2}\right)$

throat area $\left(\mathrm{m}^{2}\right)$

servo-valve restriction areas $\left(\mathrm{m}^{2}\right)$

experiment $j$

frictional force $(\mathrm{N})$

friction coefficient $(\mathrm{N} \mathrm{s} / \mathrm{m})$

servo-valve parameters $(\mathrm{mm})$

$(\mathrm{mm} / \mathrm{V})$

thermal conductance at equilibrium conditions $(\mathrm{W} / \mathrm{K})$

actuator stroke $(\mathrm{mm})$

mass flow entering or leaving the

cylinder chamber $(\mathrm{kg} / \mathrm{s})$
$M$

$\mathrm{M}_{i}$

MSE

$\overline{\mathrm{MSE}}$

$n$

$P$

$P_{\mathrm{A}}, P_{\mathrm{B}}$

$P_{\mathrm{s}}$

$P_{\mathrm{u}}, P_{\mathrm{d}}$

$P_{0}$

$\dot{Q}$

$R$

slpm

$T$

$T_{\mathrm{amb}}$

$T_{\text {in }}$

$T_{\mathrm{u}}$

$T_{0}$

V

$V_{\mathrm{d}}$

$x, \dot{x}, \ddot{x}$

$x_{\mathrm{v}}$

$x_{0}$

$\gamma$

$\lambda$

$\lambda_{0}$

$\phi$

\section{APPENDIX 2}

\section{Equilibrium pressure}

Consider the half-bridge model of a servo-valve represented in Fig. 12. $\dot{m}_{1}$ and $\dot{m}_{2}$ represent the leakages of restriction 1 and restriction 2 (see Fig. 1) and the spool is at the central position. At equilibrium $T_{\mathrm{s}}=T, A_{1}=A_{2}$, and $\dot{m}_{1}=\dot{m}_{2}$. In the typical situation where $P_{\mathrm{s}} \geqslant 3.6 P_{\mathrm{atm}}$, there are three possible situations: 


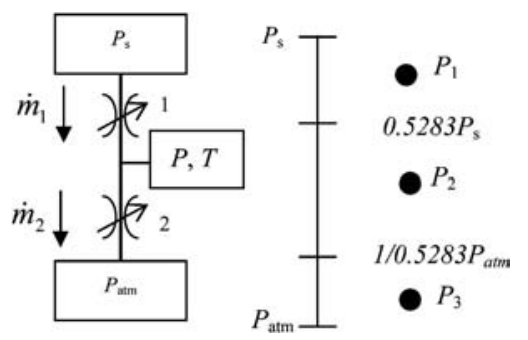

Fig. 12 Half-bridge model of a servo-valve

$P=P_{1}, P_{1} \in\left[0.5283 P_{\mathrm{s}}, P_{\mathrm{s}}\right], P=P_{2}, P_{2} \in\left[1 / 0.5283 P_{\mathrm{atm}}\right.$, $\left.0.5283 P_{\mathrm{s}}\right]$, and $P=P_{3}, P_{3} \in\left[P_{\mathrm{atm}}, 1 / 0.5283 P_{\mathrm{atm}}\right]$. In the first situation, $\dot{m}_{1}$ is subsonic and $\dot{m}_{2}$ is sonic. In the second situation, $\dot{m}_{1}$ and $\dot{m}_{2}$ are sonic. In the third situation, $\dot{m}_{1}$ is sonic and $\dot{m}_{2}$ is subsonic.
Equalizing $\dot{m}_{1}$ and $\dot{m}_{2}$ in the first situation gives

$$
\begin{gathered}
A_{1} P_{\mathrm{s}}\left\{\frac{2 \gamma}{(\gamma-1) R T_{\mathrm{s}}}\left[\left(\frac{P}{P_{\mathrm{s}}}\right)^{2 / \gamma}-\left(\frac{P}{P_{\mathrm{s}}}\right)^{(\gamma+1) / \gamma}\right]\right\}^{1 / 2} \\
=\frac{2}{\gamma+1}^{1 /(\gamma-1)}\left[\frac{2 \gamma}{(\gamma-1) R}\right]^{1 / 2} \frac{P A_{2}}{T^{1 / 2}}
\end{gathered}
$$

The solution for equation (17) when the fluid is air, which is assumed to be a perfect gas, gives $P=0.8077 P_{\mathrm{s}}$. Note that the same exercise when applied to the second and third situations would result in false propositions. 
Copyright of Proceedings of the Institution of Mechanical Engineers -- Part I -- Journal of Systems \& Control Engineering is the property of Professional Engineering Publishing and its content may not be copied or emailed to multiple sites or posted to a listserv without the copyright holder's express written permission. However, users may print, download, or email articles for individual use. 